\title{
MULHERES VÍTIMAS DE ESTUPRO: CONTEXTO E ENFRENTAMENTO DESSA REALIDADE
}

\author{
Sandra Sudário \\ Paulo César de Almeida \\ Maria Salete Bessa Jorge \\ Universidade Estadual do Ceará
}

RESUMO: Este artigo, parte da dissertação de mestrado da autora, analisa o contexto do estupro e seu enfrentamento pelas mulheres vitimadas e descreve o comportamento do estuprador com base na percepção da vítima. Cinco mulheres atendidas em um hospital de referência em HIV/AIDS responderam a entrevistas semi-estruturadas submetidas à técnica de análise de conteúdo. Os resultados evidenciaram a vulnerabilidade da mulher, não somente em lugares ermos e vias públicas, mas também no trabalho e residência. Diante da frieza e crueldade do estuprador, que manifesta oscilações comportamentais variáveis, desde ameaças de morte até choro após a violência, a mulher lança mão de estratégias de libertação e sobrevivência. A busca pelo atendimento configura-se em uma verdadeira via-crucis. Entretanto, a despeito dos traumas adquiridos, as mulheres mostraram profunda resiliência.

PALAVRAS-CHAVE: estupro; violência; mulher.

\section{WOMEN RAPE VICTIMS: EXPERIENCES AND CONFRONTATION OF THIS REALITY}

ABSTRACT: This article, as part of the authors' dissertation for her Masters degree, analyzes the experience of rape and the way victims face the problem. It also describes the behavior of the rapist based on the victims' view. Five women, who were being attended in a HIV/AIDS reference hospital, answered semi-structured interviews that were submitted to the technique of content analysis. The results show the vulnerability of woman, not only in deserted places and public ways but also at work and at home. The victims use strategies of liberation and survival at the moment of rape, in face of the rapist who reveals himself as being cruel and cold, with emotional oscillations that may vary from death threats to crying after the rape. Reaching out for assistance constitutes a real via cruxes for the victims. However, despite the traumas, they have demonstrated a profound capacity of resilience.

KEY WORDS: rape; violence; woman.

Os efeitos deletérios do estupro sobre a vida e a saúde das mulheres, e a magnitude da sua incidência, têm se configurado como um problema de saúde pública, atingindo suas vítimas nas diversas faixas etárias, independente de classe social, raça, etnia, religião, idade e grau de escolaridade. Embora a verdadeira incidência dos crimes sexuais seja desconhecida, acredita-se ser essa uma das condições de maior sub-notificação e subregistro. Segundo Oliveira (2000), com base em dados da Organização das Nações Unidas, um quarto de todas as mulheres do mundo são estupradas pelo menos uma vez na vida. De acordo ainda, com outras estimativas, esse crime acomete 12 milhões de mulheres em todo o mundo a cada ano. Apenas nos Estados Unidos da América (EUA) cerca de 683 mil mulheres adultas são estupradas por ano, 200 mil crianças são sexualmente abusadas e a cada 6,4 minutos ocorre uma agressão sexual (Drezett, 2002).

Além disso, estudos de base populacional realizados em diversos países revelaram prevalência de crimes sexuais que variam entre 5,1 e $29 \%$. Provavelmente a grande variabilidade nesses dados está influenciada pelo método utilizado na investigação, pela definição de violência sexual e pelas diferenças culturais entre os diversos países e regiões (Heise \& cols., 1994, citado em Andalaft \& Faúndes, 2001).

No Brasil uma Comissão Parlamentar de Inquérito (CPI) destinada a investigar a questão da violência contra a mulher, abrangendo 20 unidades da Federação, de janeiro de 1991 a agosto de 1992, destacou três estados onde os percentuais de estupro relacionados ao total de delitos cometidos contra as mulheres eram exageradamente altos: Alagoas, (13,3\%), Pernambuco, (19,1\%) e Espírito Santo, $(19,8 \%)$ (Saffior \& Almeida, 1995). Teixeira (1998) chama a atenção para os estudos que ressaltam a elevada incidência dos crimes sexuais nos Estados Unidos da América, e conforme estima, comparativamente, no Brasil, deve acontecer mais de 1000 estupros por dia.

No Ceará, os dados parecem fragmentados. A Secretaria Nacional de Segurança Pública mostra o município de Fortaleza com 65 casos relatados no ano 2000 nas ocorrências criminais tipificadas como estupro e 66 como atentado violento ao pudor. No mesmo ano, a Delegacia de Mulheres registrou em suas ocorrências, 35 casos de estupro, enquanto o IML realizou 410 exames de estupro. Outra fonte de consulta, o relatório emitido pela Câmara Municipal de Fortaleza também no ano 2000 revela a ocorrência de 32 queixas de estupro naquele ano, embora as estimativas apontadas pelo mesmo relatório deixem claro que a quantidade de mulheres vítimas de estupro pode chegar a 450 por ano (Brasil. Ministério Da Justiça, 2003; Fortaleza. Prefeitura, 2000).

O trabalho ora desenvolvido analisa o contexto no qual ocorreu o estupro e o enfrentamento dessa realidade em um grupo de mulheres atendidas em um hospital público de Fortaleza e objetiva, também, descrever o comportamento do estuprador a partir da percepção da vítima. Diante desta realidade, espera-se, com este estudo, contribuir para a visualização do crime do estupro; oferecer 
subsídios para a compreensão de alguns aspectos dessa violência sexual e estimular o desenvolvimento de políticas públicas destinadas a amparar as mulheres vitimadas.

\section{Método}

Caracterizada como descritiva, a pesquisa foi desenvolvida em um hospital público do Ceará, referência em doenças infecciosas e HIV/AIDS, que atendeu uma demanda de 41 casos de estupro nos anos de 1999 a 2003.

A opção pelo campo de pesquisa mencionado explicase pela experiência da autora, que desde 1999 começou a vivenciar o atendimento dessas mulheres e pela visualização da possibilidade de um acesso mais facilitado às cinco participantes do estudo, porquanto as 41 mulheres já haviam procurado anteriormente a instituição hospitalar pelo menos uma vez. Esse acesso ocorreu em virtude do vínculo estabelecido por ocasião dos seus retornos ao hospital e da existência de um dado fundamental nos registros: o número de seus telefones. Antes de optar pela instituição mencionada, a autora buscou com recursos próprios localizar algumas mulheres vítimas de estupro e que haviam sido atendidas em outra instituição. Como não havia registros dos seus telefones, apenas o nome da rua onde moravam, não havia alternativa senão ir até suas residências. Entretanto, nos locais em que supostamente residiriam as vítimas, seus moradores afirmavam não conhecer ninguém ali com tal nome, apesar de alguns residirem ali há cinco ou até dez anos. Essas dificuldades reforçaram a escolha da instituição hospitalar, a qual registrava apenas o telefone das mulheres.

Quanto aos critérios de inclusão da investigação, constituíram-se de mulheres a partir de 18 anos que sofreram estupro perpetrado por indivíduos não pertencentes ao seu círculo familiar ou afetivo, enquanto os critérios de exclusão foram delimitados pelas mulheres a partir de 18 anos que sofreram estupro perpetrado por indivíduos pertencentes ao seu círculo familiar ou afetivo e pelas mulheres menores de 18 anos, independente do grau de relacionamento com o agressor. A escolha destes critérios justifica-se pela opção de trabalharmos com a idade legal. Desse modo, os princípios éticos e legais a serem respeitados não se tornariam um limite para a pesquisa. Acrescidos a isto, havia-se observado uma predominância desta faixa etária nos atendimentos e o desconhecimento dos agressores relatados pelas vítimas.

Por telefone, foram contatadas 41 mulheres. Após cerca de 150 telefonemas, cinco decidiram conceder as entrevistas. Por solicitação de duas mulheres as entrevistas com elas foram realizadas em suas residências. As demais preferiram, uma a universidade em que estudava; outra a casa da empresária para quem trabalhava e a última, o interior do veículo da autora. Portanto, este momento da pesquisa não foi definido pela quantidade, mas sim pela profundidade das informações coletadas, demonstrando a capacidade de responder aos objetivos delimitados e às dimensões surgidas no contexto das mulheres vitimadas pelo estupro. Com vistas a preservar a identidade das participantes, as mulheres foram identificadas no estudo com nomes de flores: Violeta, Margarida, Rosa, Tulipa e Flor de Liz.

As questões éticas estabeleceram-se por meio da Resolução 196/96 do Conselho Nacional de Saúde (Conselho Nacional de Saúde, 1996).

$\mathrm{Na}$ organização das informações foram adotados os seguintes passos: a) constituição do corpus - o corpus da pesquisa foi constituído de cinco relatos de entrevistas semi-estruturadas; b) definição da unidade de registro - a frase e unidade de contexto - o parágrafo; c) recorte do texto com a finalidade de constituir o inventário; d) definição das subcategorias e, posteriormente, por semelhanças, as categorias; e) agrupamento das categorias por analogia, com a finalidade de construir os temas (Bardin, 1977).

\section{Resultados}

\section{Perfil das Mulheres Entrevistadas}

- Tulipa: 30 anos, solteira, costureira, residente em um bairro periférico da cidade de Fortaleza com os dois filhos. Entrevistada após um ano e um mês do episódio.

-Violeta: 26 anos, pedagoga, solteira, residente com a família em um bairro nobre da cidade de Fortaleza, não tem filhos. Entrevistada dois meses após o estupro.

- Margarida: 30 anos, secretária executiva, solteira, residente com sua mãe em um bairro central da cidade de Fortaleza, uma filha de 8 anos. Entrevistada dois meses após o estupro.

- Rosa: 34 anos, agente de saúde, casada, residente em um local próximo a uma BR em Fortaleza com o marido e dois filhos do casal. Entrevistada sete meses após o estupro.

- Flor de Liz: 22 anos, universitária, solteira, sem filhos, residente em bairro nobre da cidade de Fortaleza com os pais. Entrevistada três anos e quatro meses após o estupro.

O contexto situacional da ocorrência do estupro perpetrado por um indivíduo não pertencente ao círculo familiar ou afetivo da vítima pode ser bastante imprevisível. Embora o senso comum visualize essa possibilidade geralmente vinculada a uma situação de suposta exposição da mulher em lugares ermos, escuros, em altas horas da noite e provavelmente sozinha, as entrevistadas mostraram que as circunstâncias que antecederam a experiência foram diversas, abrangendo situações, tais como estar na companhia de um amigo na hora do lazer; percorrer o trajeto do trabalho para a residência; por ocasião de uma carona; encontrar-se em sua residência dormindo ou estar no ambiente de trabalho. Essa revelação, inserida na conjuntura atual que retrata a violência de forma abrangente, é compreensível na medida em que não há lugar totalmente seguro nas cidades, seja o reduto do lar, o recinto de trabalho ou as vias públicas.

Mais surpreendente é constatar que essa vulnerabilidade da mulher, em particular, estende-se também a situações estarrecedoras, tais como sair de casa para prestar vestibular e acabar sendo estuprada e morta em um banheiro pertencente às instalações da Universidade (O Povo, 2000). Tais situações são ilustradas nas falas: 
Eu estava com um amigo, vendo o pôr-do-sol. A gente já tava indo embora e eu vi os dois subindo num barranco. (Violeta)

Eu tava saindo da empresa e fui abordada por um cidadão (Margarida).

Eu saí de casa, ia marcar uma consulta pro meu filho, lá no Hospital Geral, eu perdi o ônibus que passou na pista, aí parou um rapaz e me deu a carona. Perguntou aonde é que eu ia e eu disse: - O senhor pode me levar até a parada seguinte, que é mais na frente? Aí ele: - Posso. Eu entrei no carro. (Rosa)

... Quando escutei uma pancada na porta, perguntei quem era e ninguém respondeu ... Aí eu dormi. Quando eu acordei ele tava dentro de casa. (Tulipa)

A abordagem da vítima no contexto do estupro pode não ser evidenciada de imediato pelo agressor. Inicialmente há um primeiro contato, muitas vezes discreto, para não assustar a vítima ou revelar a atitude do marginal diante de pessoas que possam surgir nas proximidades (Silva, 2000).

Nos casos estudados, conforme observou-se, os estupradores aproximaram-se das vítimas a princípio com atitudes dissimuladoras, ora aparentando um comportamento típico de um namorado, ora forjando ser um assaltante, e ainda oferecendo carona com segundas intenções.

As abordagens geralmente foram seguidas de ameaças de morte com arma, sendo a arma branca ou a de fogo as mais utilizadas para intimidar as vítimas. Esse aspecto é explicitado por Kaplan e Sadock (1990, p.397), ao mencionarem que "o estuprador sempre ameaça a vítima com seus punhos, revolver, ou faca...".

Nenhuma das entrevistadas referiu ter tido seus pertences roubados, apesar de oferecê-los. Nos casos estudados, mesmo quando o estupro foi praticado por marginal acompanhado de comparsa, era o outro que assaltava e jamais a vítima do estupro era o alvo do assalto e sim quem estava com ela ou próximo dela. Esses acontecimentos são ilustrados pelas seguintes falas:

\footnotetext{
.. Me pegou pela cintura, disse prá eu manter a calma e fazer de conta que ele era meu namorado... (Margarida) Quando chegou no local em que eu ia parar, ele não parou, me levou direto. (Rosa)

... Renderam a gente, um com um revólver 38 e outro com uma pistola ... Colocaram a gente no porta-malas, o tempo todo ameaçando a gente de morte ... Um deles levou meu amigo pro Banco, enquanto eu ficaria com o outro. (Violeta)

... O tempo todo com a arma na minha cabeça. (Margarida) ... Colocou já a faca no meu pescoço. (Tulipa)
}

A experiência vivenciada pelas vítimas de estupro deixa muitas seqüelas na vida e na saúde das mulheres atingidas por esta violência e em uma escala diferente também afeta seus familiares, além de comprometer o tecido social como um todo. Nesse contexto, o comportamento do estuprador é um aspecto importante relatado pelas vítimas de estupro ao descrever a experiência vivenciada. Poucos estudos, porém, abordam essa particularidade. Alguns pesquisadores, baseados em relatos pessoais de médicos que atenderam mulheres violentadas, discorrem sobre a possibilidade do estuprador agir conforme o comportamento da vítima e falam de um certo controle do marginal por esta, afirmando que algumas mulheres, embora em número bastante reduzido, têm conseguido, a despeito da tensão e do medo, utilizarem-se de artifícios, como masturbar o agressor ou fazê-lo usar o preservativo masculino, na intenção de se protegerem pelo menos quanto às DST/HIV/AIDS (Oliveira, 2000).

Entretanto, neste estudo, conforme se deduz pelas entrevistadas, não se deve esperar coerência no comportamento destes marginais, quer a mulher aja de uma maneira, quer de outra, sendo arriscado postular condutas a serem assumidas diante do estuprador. Independentes da reação da vítima, estes podem ter reações imprevisíveis. Ademais, existe a possibilidade de alguns desses indivíduos serem mais ou menos agressivos, a depender de estarem ou não sob o efeito de drogas, ou eventualmente terem distúrbios mentais severos, o que não foi possível demonstrar no presente estudo. Convém lembrar, no entanto, um aspecto importante levantado por Kaplan e Sadock (1990), qual seja: o estuprador tem necessidade de expressar raiva e poder e recorre ao estupro para manifestar isso. Portanto não é a temática do sexo o que o atrai e sim necessidades não-sexuais. Esses estudiosos não classificam o estuprador como pessoa portadora de distúrbio sexual. Segundo eles entendem, o estupro é um ato de violência e humilhação que se expressa pelos meios sexuais, sendo mais apropriado discuti-lo sob o título de agressão. Ressaltam, entretanto, que os estupradores sádicos caracterizados por comportamento homicida, estes, sim, apresentam distúrbio esquizofrênico subjacente.

Pelos relatos, como se pôde constatar, o perpetrador assume comportamentos diferentes no momento do estupro e imediatamente após este. No momento do estupro, os estupradores podem ser frios e cruéis, não respondendo aos apelos e súplicas das vítimas, agindo numa escala ascendente de intimidação e violência. Sobre isso, Kaplan e Sadock (1990, p.397) afirmam que "a mulher que está sendo estuprada está, freqüentemente, em situação de risco de vida".

Após o estupro, segundo constatado, os agressores apresentaram comportamentos bem distintos, desde a formalização de ameaças de morte às vítimas ante a possibilidade da denúncia por parte delas, até labilidade emocional, imposição do perdão pelo delito cometido e propostas de encontros futuros com a vítima. Para uma melhor compreensão das oscilações comportamentais desses indivíduos, e da violência por eles perpetrada, alguns autores foram consultados. Entre eles Kaplan e Sadock (1990, pp.396-397), que após revisarem pesquisas envolvendo estupradores presidiários, reforçam suas convicções sobre o assunto:

O crime é cometido para aliviar uma energia agressiva demasiadamente intensa contra pessoas pelas quais o estuprador tem algum respeito. Embora essas pessoas admiradas sejam geralmente homens, a violência vingativa é dirigida às mulheres. Esta descoberta encaixa-se na teoria feminista, que propõe que a mulher serve de objeto ao deslocamento da agressão que o estuprador não pode expressar diretamente contra outros homens. A mulher é considerada propriedade ou posse vulnerável dos homens. 
Não obstante as considerações levantadas pelos autores mencionados, alguns estudiosos preferem enquadrar o estuprador em descrições estereotipadas. Vargas (1999) descreve os perpetradores de estupro desconhecidos das vítimas como indivíduos jovens de estrato social mais baixo, que têm desvio de comportamento sexual, têm problemas de timidez ou são impotentes.

É necessário, porém, se desenvolver mais pesquisas voltadas para a compreensão desses indivíduos estupradores, numa abordagem ética, no sentido de estudar suas mentes, seu cotidiano e seu comportamento, visto que a temática do estupro é também parte das questões humanas, embora nos seus aspectos mais destrutivos. Rotular essas pessoas de monstruosas, como se não fizessem parte da raça humana, não é a solução. Atitudes como estas acabam favorecendo um distanciamento ainda maior da problemática e dificultam seu aprofundamento em estudos e pesquisas, principalmente relacionados às suas raízes. Algumas falas retratam bem a situação vivenciada pelas vítimas e o comportamento do estuprador:

\footnotetext{
... Ele me botava na água, que era uma queda dágua, um tipo... como se fosse um esgoto... me colocava embaixo... prá eu ficar sem respirar... prá eu não tentar reagir... muito frio... muito calmo... me ameaçou... fez roleta russa na minha cabeça. (Violeta)

.. Quando terminou, ele começou a chorar, pedindo desculpas, pedindo pelo amor de Deus que eu o perdoasse, que isso não era uma coisa normal dele, que ele nunca tinha feito isso. (Margarida)
}

O confronto entre a reação e o risco de perder a vida é um dilema incalculável vivenciado pelas vítimas, onde a questão maior da sobrevivência geralmente predomina, deixando em uma graduação menor a humilhação sofrida, a dor física e psicológica de ter sua integridade violada em todos os sentidos para enfim, numa atitude de impotência e submissão, render-se ao agressor. Esse aspecto é lembrado por Hampton (1995), quando relata que o maior medo das vítimas desse tipo de violência é a morte. Entretanto, conforme se percebeu pelos relatos, as vítimas de estupro, apesar de serem compelidas a não reagirem, tentam elaborar estratégias de libertação e de sobrevivência desde o primeiro momento em que se deparam com o agressor até este concretizar a violência. Então, no momento em que oferecem seus pertences materiais, gritam ou calam, fingem aceitar as propostas do estuprador para encontros futuros, falam o que são obrigadas a falar, fazem o que são obrigadas a fazer, concordam com o perdão imposto pelo marginal ou fazem orações silenciosas, tudo isso pode ser indício de que a mulher não pára de lutar. Todavia, não se deve esquecer que ela tem sempre em mente o risco de morrer. Isso é exteriorizado pelas falas:

\footnotetext{
... Se eu tivesse reagido, eu tenho certeza que eu teria morrido. (Violeta)

... Não tinha como gritar, se eu gritasse ninguém ia escutar. (Tulipa)
}

... Que eu cedi a tudo o que ele quis fazer. (Margarida)

... Tudo o que ele mandava eu fazia. (Flor de Liz)

Outra categoria surgida nos relatos foi a dos sentimentos vivenciados pela vítima após o estupro. Conforme diversos estudos têm mostrado os sentimentos vivenciados pela mulher em situação de violência causam grande impacto, tanto na sua vida pessoal como na familiar (Bergamo \& cols., 2000; Faúndes, 2000; Saffiori \& Almeida, 1995).

Pelos relatos das entrevistadas, como observou-se, o medo foi um dos sentimentos mais predominantes instalados nas vítimas. Entre eles destacam-se: ter adquirido o vírus HIV; reencontrar o estuprador; sair de casa; ficar sozinha e contar o fato aos familiares e parceiro. O sentimento de raiva não foi expresso, sendo substituído por pena do estuprador. Isto, em um caso específico pode estar relacionado ao fato da vítima ter participado de todo o processo de reconhecimento do estuprador. Ela própria o apontou como tal, e além disso, deparou-se com a precariedade dos presídios e com o tratamento dispensado aos presidiários. Outra possível explicação seria a omissão da raiva ainda como uma resposta traumática ao sofrimento. A culpa também esteve muito presente nos depoimentos, mas o medo de engravidar, enfatizado por alguns autores, a exemplo de Maia e cols. (2000), não foi relatado. Na ilustração dessa realidade algumas falas são mostradas a seguir:

\footnotetext{
.. Cada exame que eu ia buscar era a mesma angústia.. quando saiu o terceiro é que eu fiquei mais aliviada, todos davam negativos... Porque jamais ele.. jamais iria aceitar uma situação dessa! Ia se tornar um inferno minha vida, se eu falasse isso prá ele. Eu ia destruir o meu casamento... Eu fiquei com esse medo assim, dele dar umas voltas por lá, me procurar, né? (Rosa)

... Eu não consigo ter raiva dele, eu não tenho raiva, eu tenho pena. (Violeta)
}

Quando a mulher que passa pela experiência do estupro é libertada pelo marginal, emerge então uma outra realidade, tão difícil de ser encarada quanto a que acabara de atravessar. Esse momento foi denominado por nós de "enfrentamento da realidade após a violência sofrida", que pode ser um demarcador de soluções a serem elaboradas no âmbito bio-psico-social e espiritual demandadas dos problemas circunscritos a esse contexto. Com quem compartilha, de que modo as pessoas do seu relacionamento a acolhem, como é o atendimento dos órgãos públicos ou privados buscados por ocasião da violência, tudo isso pode contribuir para a estruturação de respostas ao sofrimento instalado. Nesse sentido, o posicionamento do Ministério da Saúde (Brasil, 2002, p.3), expresso na Norma Técnica sobre violência sexual afirma:

O enfrentamento da violência exige a efetiva articulação de diferentes setores, tais como saúde, segurança pública, justiça e trabalho, bem como o envolvimento da sociedade civil organizada, configurando redes integradas de atendimento. 
Para Kaplan e Sadock (1990), os sistemas de apoio disponíveis à mulher imediatamente após a agressão influenciam nas manifestações e no grau dos danos causados àquela vitimada pelo estupro, independente da violência do próprio ataque. Torna-se claro, portanto, a importância de uma rede de apoio capaz de amparar integralmente as mulheres vitimadas pelo estupro, contemplando suas necessidades e problemas advindos da violência experienciada. Essa rede de apoio foi assinalada pelos discursos das mulheres, e abrange a família, amigos, parceiro, trabalho, serviços de saúde, serviço policial, serviço médico-legal e Deus.

Nas falas das mulheres estudadas, a família aparece como estrutura de apoio, mediante suporte emocional e financeiro, procurando encarar o fato com a naturalidade possível de demonstrar nessa situação. No entanto, segundo algumas falas externam, o estupro ocorrido, às vezes, é omitido até mesmo dos familiares, inclusive do marido. Muitas vezes apenas um membro da família toma conhecimento da situação e nesse caso geralmente é uma das irmãs da vítima.

O ambiente de trabalho, quando não identificado como o local da ocorrência, foi percebido nas falas como de grande importância para a reestruturação da vida das mulheres, embora possa se constituir também, no local de maiores expectativas relacionadas ao estigma do estupro.

Um ponto a ser considerado é a resposta do setor de saúde. Este, tanto para prevenir quanto para tratar os agravos resultantes da violência sexual, tem sido fragmentado. As considerações ouvidas das entrevistadas chamavam a atenção para problemas como a distribuição dos anti-retrovirais e a falta de divulgação do serviço, enfatizando que geralmente é alguém do relacionamento pessoal pertencente à área de saúde a ponte para chegarem até a instituição. Outro aspecto expressado nas falas das mulheres foi a escolha da rede de atendimento privado pelas vítimas de melhor poder aquisitivo, ficando o atendimento da instituição pública restrita ao recebimento dos antiretrovirais, imunobiológicos e orientações sobre a conduta a ser seguida.

Pelos relatos das entrevistadas que procuraram as delegacias, pôde-se observar certa atuação da polícia, no relacionado às tentativas de reconhecimento do estuprador, o que inspirou esperanças nas mulheres vitimadas, dado que, como já evidenciado neste estudo, um de seus maiores medos é o de reencontrar o marginal. Porém, em apenas um dos cinco casos estudados, houve a prisão deste. Neste caso, ressalta-se a influência social dos parentes desta vítima, que agilizaram os trâmites. A falta de informação foi um item constatado em relação ao atendimento recebido, bem como a falta de um acolhimento digno, solidariedade e ética. A dúvida dos policiais quanto à veracidade do fato também foi observada nos relatos, $\mathrm{o}$ que causou profunda indignação por parte das mesmas. Conforme se sabe, muitas mulheres não formalizam a queixa do estupro nas delegacias de polícia devido ao constrangimento e descrédito na ação policial. Segundo o Ministério da Saúde (Brasil, 2002), menos de 10\% dos casos chegam às delegacias.
Maia e cols. (2000) mencionam o constrangimento da mulher vitimada relacionado à discriminação da sociedade, que passa a idéia segundo a qual a mulher estuprada é aquela que dá motivos ou provoca a situação ou de que só é considerado estupro aquele em que a mulher é espancada, machucada fisicamente ou até morta.

Além disso, uma parcela da população que denuncia nas delegacias não procura o atendimento médico-legal. Essa realidade foi constatada nos relatos das mulheres e nos casos atendidos na instituição de saúde, campo desta pesquisa. As falas das entrevistadas que utilizaram esse serviço mostraram um constrangimento por ocasião do exame de corpo de delito, apesar de terem enfatizado a importância do procedimento como necessário à comprovação do fato diante das autoridades judiciais. Algumas falas exteriorizaram satisfação e agilidade no atendimento. No entanto, houve o relato de um caso no qual o examinador médico submeteu a cliente no momento do exame a interrogatórios irônicos, no intuito de responsabilizá-la pela violência sofrida. Isto aumentou o sofrimento da vítima e causou péssima impressão a respeito do atendimento.

Provavelmente um dos aspectos mais dolorosos para a mulher vitimada pelo estupro, ao enfrentar a nova realidade a ser assumida, é a trajetória percorrida na busca pelo atendimento. Não seria exagero denominar esse caminho como via-crucis, visto que a mulher vítima desta violência, para ter suas necessidades contempladas, pode percorrer até cinco instituições ou até mais, a depender dos agravos resultantes da violência. Isso se torna mais grave, não somente pelo tempo e pelo transtorno de se deslocar para tantos lugares, mas, principalmente, pela exposição da mulher, que precisa narrar a mesma história diversas vezes.

Com base na realidade estudada, e conforme observouse, o atendimento de saúde pode constar de três instituições: uma faz a profilaxia e controle das DST, HIV/ AIDS, incluindo a monitoração da toxicidade dos antiretrovirais, a imunização da Hepatite B e sorologias para Hepatite B; Hepatite C e Sífilis. Outra faz a prevenção da gravidez indesejada e o aborto garantido pela lei, caso haja gravidez e opção pela interrupção por parte da mulher. A imunoglobulina para a hepatite B é oferecida em uma instituição diversa das anteriores. Há casos também nos quais as mulheres complementam o atendimento da rede pública com o da rede privada. Acrescenta-se a estas as instituições vinculadas à Secretaria de Segurança Pública, que são as delegacias de polícia e IML.

Andalaft e Faúndes (2001) ao analisarem a resposta do setor saúde às vítimas de violência sexual, declaram que a situação do atendimento tem avançado no país, passando de três serviços em dois estados, em junho de 1997, a 22 em sete estados em junho de 2000. Em dezembro de 2000, complementam os autores, foram identificados 53 hospitais com serviço de atenção a mulheres vítimas de violência sexual em 20 estados brasileiros, com estimativas para 2001 de mais de 71 hospitais com serviço em todos os estados brasileiros.

Ainda sobre o enfrentamento da violência sofrida pelas mulheres vitimadas pelo estupro, outro aspecto 
observado nas falas das entrevistadas foi a conseqüência psicológica do episódio, destacando-se indícios de transtorno por estresse pós-traumático, entidade que apresenta características particulares na população de mulheres adultas vitimadas por estupro, tanto pelo modo de manifestação clínica, quanto pelos impactos causados à mulher.

Segundo Bergamo e cols. (2000), na fase aguda do transtorno, também conhecida por desorganização, a mulher pode experimentar uma série de emoções tais como angústia, medo, ansiedade, degradação, humilhação, vergonha, culpa, autocensura e até mesmo uma forma mascarada de domínio e controle da situação, que não reflete o sofrimento pelo qual está passando. Em seguida, a mulher entra na segunda fase, conhecida como intermediária ou de ajustamento exterior, na qual ela tenta negar o estupro e voltar às suas atividades normais. A terceira fase é a fase tardia ou de reorganização. Trata-se de um processo a longo prazo, de meses a anos, podendo surgir inúmeros problemas vaginais ou distúrbios menstruais, assim como depressão, fobias, repulsa e aversão pelo sexo masculino, diminuição ou perda da facilidade orgástica.

Como se pôde constatar, tanto as vítimas recentes de estupro quanto as mais antigas vivenciavam ainda o trauma decorrente do evento. Todavia, em virtude das limitações desta pesquisa, as fases do transtorno não foram aqui diagnosticadas, sendo descritos apenas os estados traumáticos atravessados pelas mulheres. Contata-se isso nas falas:

\footnotetext{
... Me afeta um pouco, tanto no meu emprego como no meu curso de especialização, que eu já tinha iniciado, porque eu tô com um problema de concentração... não consigo me concentrar bem, eu não consigo... é... ficar muito tempo lendo uma coisa ... logo fico dispersa... O que mais me incomoda hoje são alguns flashes que eu fico tendo o tempo inteiro... pesadelo é o que me incomoda mais. (Violeta)
}

Outros aspectos provavelmente influenciam nas respostas dessas mulheres aos traumas vivenciados, e precisam ser investigados. Entre eles, padrões culturais, como as crenças; o estigma que permeia a temática do estupro; a rede de apoio que dá suporte à mulher vitimada e a história de vida de cada mulher.

A despeito de toda a complexidade a envolver a nova realidade a ser enfrentada pelas mulheres afetadas pela problemática do estupro e do sofrimento traumático mostrado também aqui neste estudo por meio dos relatos, observou-se que elas demonstram impressionante capacidade de resiliência, não se apoiando na vitimização para dar prosseguimento às suas vidas e sim buscando superar as adversidades surgidas a partir da violência sofrida.

\section{Considerações Finais}

Os modos de enfrentamento da realidade insurgida a partir do estupro vão ser demarcadores das soluções biopsico-socio-espirituais a serem elaboradas a curto, médio e longo prazos, circunscritas ao contexto vivenciado. A mulher vitimada pelo estupro não tem ainda a proteção garantida ao cidadão via constituição. Torna-se, portanto, vítima também da omissão do Estado e mesmo da sociedade, ambos incapazes de desenvolver medidas eficazes de prevenção, controle e tratamento dessa violência. Apesar do preconizado pelo Ministério da Saúde, há um grande distanciamento entre o que ele recomenda para o atendimento dessas mulheres e o que oferece e se consegue palpar na realidade em termos da atenção dispensada. Isso também reflete o quadro de instabilidade no país em relação às questões de segurança pública e evidencia a urgência de enfrentamento e transformação dessa realidade.

\section{Referências}

Andalaft, J. \& Faúndes, A. (2001, junho). A violencia sexual y la respuesta del setor salud en Brasil. Em [editores] Simpósio 2001: Violencia de genero, salud y derechos en las Américas, Cancún, México.

Bardin, L. (1977). Análise de conteúdo. Lisboa: Edições 70.

Bergamo, W. (2000, setembro). [quem são os outros autores?] et al. Papel do Ginecologista diante de Paciente Vítima de Estupro. Femina, 28(8), xx-xx.

Brasil - Conselho Nacional de Saúde (1996). Resolução n. 196, de 15/04/1996 (Aprova normas regulamentadoras de pesquisa envolvendo seres humanos). Brasília, DF: Autor.

Brasil - Ministério da Saúde (2002). Norma técnica prevenção e tratamento dos agravos resultantes da violência sexual contra mulheres e adolescentes ( $2^{\mathrm{a}}$ ed.). Brasília, DF: Autor.

Brasil - Ministério da Justiça (2003). Ocorrências criminais / perfil das policias. Acessado em 21/02/2003 em http:// www.mj.gov.br.senasp

Drezett, J. (2002, novembro). Aspectos biopsicossociais da violência sexual. Jornal da rede feminista de saúde, 22 , xx$\mathrm{xx}$.

Faúndes, A. (2000). Assistência Integral à mulher vítima de violência sexual. Jornal Febrasgo, 7(4), 4-5.

Fortaleza - Prefeitura Municipal de Fortaleza (2000). Relatório Final da Comissão Especial da Câmara Municipal para Diagnosticar a Violência Contra a Mulher na Cidade de Fortaleza. Fortaleza, CE: Câmara Municipal de Fortaleza.

Hampton, H.L. (1995, junho). Cuidados com a mulher violentada. Ginecologia Obstetricia, 4(6), xx-xx.

Kaplan, H.I. \& Saddock, B.J. (1990). Compêndio de Psiquiatria ( $2^{\mathbf{a}}$ ed.). Porto Alegre: Artmed.

Maia, C.A.T. \& cols. (2000, abril). Mulheres vítimas de violência sexual: atendimento multidisciplinar. Femina, 28(3), 155-161.

Oliveira, F. (2000). Reflexão e ação feminista sobre violência de gênero e saúde. Jornal Febrasgo, 7(4), 6-7.

Pedrosa, L. (2000, novembro). Tragédia no vestibular da UFC. $O$ Povo, 20, xx-xx.

Saffiori, H.B. \& Almeida, S.S. (1995). Violência de gênero: poder e impotência. Rio de Janeiro: Revinter.

Silva, S. S. (2000). A Mulher Vítima de Estupro: suas vivências e incertezas. Monografia do Curso de Especialização em Saúde da Família da Universidade Federal do Ceará, 42.

Teixeira, W.R.G. (1998). A importância do swab na perícia de estupro. Revista IMESC, 1(dezembro),

Vargas, J.D. (1999, junho). Familiares ou desconhecidos? A relação entre os protagonistas do estupro no fluxo do Sistema de Justiça Criminal. Revista Brasileira de Ciências Sociais, 14(40). 
Sudário, S., Almeida, P.C. \& Jorge, M.S.B. "Mulheres Vítimas de Estupro: Contexto e Enfrentamento dessa Realidade".

Sandra Sudário é Mestre Enfermeira do Hospital São José.

Endereço: Av. Santos Dumont, 6911/1102, Papicu, 60190 800,

Fortaleza, CE. E-mail: sandysudario@bol.com.br

Paulo César de Almeida é Docente de estatística do Mestrado

em Saúde Pública da UECE. Endereço é: Av. Paranjana, 1700,

Campus do Itaperi, Fortaleza, CE.

E-mail: pc_almeida@zipmail.com.br

Maria Salete Bessa Jorge é Docente e Vice-Coordenadora do

Mestrado em Saúde Pública da UECE.

E-mail: masabejo@zaz.com.br

Sandra Sudário, Paulo César de Almeida e Maria Salete

Bessa Jorge

Mulheres vítimas de estupro: contexto e enfrentamento

dessa realidade

Recebido: 01/04/2005

$1^{a}$ revisão: 24/10/2005

Aceite final: 24/11/2005 